\title{
A pilot study of Helicobacter pylori genotypes and cytokine gene polymorphisms in reflux oesophagitis and peptic ulcer disease
}

\author{
Akdogan RA 1 , Ozgur $\mathrm{O}^{2}$, Gucuyeter $\mathrm{S}^{3}$, Kaklikkaya $\mathrm{N}^{3}$, Cobanoglu $\mathrm{U}^{4}$, Aydin $\mathrm{F}^{3}$ \\ Recep Tayyip Erdogan University, School of Medicine, Department of Internal Medicine, Division of Gastroenterology, Rize, \\ Turkey.remziadnan@yahoo.com
}

\begin{abstract}
Helicobacter pylori causes various diseases such as chronic gastritis, peptic ulcer and gastric cancer. While majority of the people infected with $\mathrm{H}$. pylori is asymptomatic, 15-20\% of them develop such diseases. The main factors, which determine the development of $H$. pylori related diseases might be bacterial virulence, host genetic and environmental factors.

The aim of this study was to reveal the factors that play a role in the disease development in patients with reflux esophagitis and peptic ulcer, infected with Helicobacter pylori. Environmental factors such as medical agents, smoking and body mass index were evaluated. The factors specific to bacteria such as vacA, CagA, babA and iceA virulence genotypes and the host factors such as IL-1, IL-2, IL-4, IL-6, IL-10, IL-12, interferon- $\gamma$, TNF- $\alpha$, ve TGF- $\beta_{1}$ gene polymorphisms were compared between the two groups.

$H$. pylori infected twenty five patients with reflux esophagitis and peptic ulcer were enrolled in the study. There was no statistical difference between the two groups regarding environmental factors. IL-2 $-330 T+166 \mathrm{~T}(\mathrm{p}=0.037)$ and IL10 $-1082 \mathrm{~A} ;-819 \mathrm{C}(\mathrm{p}=0.049)$ gene polymorphisms were significantly more common in the group of patients with peptic ulcer compared to the group with reflux esophagitis. In both groups of patients, either with reflux esophagitis or peptic ulcer, multiple H. pylori virulence genotypes (cagA, vacA, babA) (mean values $74 \%, 78 \%, 54 \%$ respectively) were observed. In this study, we revealed that cytokine gene polymorphisms may play a role in the development peptic ulcer while $H$. pylori virulence genotypes seem to be crucial for the development of associated diseases (Tab. 4, Ref. 51). Text in PDF www.elis.sk.

Key words: Helicobacter pylori genotypes, single nucleotide polymorphisms, reflux oesophagitis, peptic ulcer.
\end{abstract}

Helicobacter pylori (H. pylori) infection is a gram-negative, microaerophilic bacteria which infects a majority of the world population (1). The most important diseases caused by $H$. pylori are duodenum and gastric ulcer, gastric adenocarcinoma and primary gastric lymphoma (2). In 1994, H. pylori was accepted as a 1st group carcinogen by the World Health Organization (3).

The reason why Helicobacter pylori infection leads to different clinical results is not exactly known, but primarily three mechanisms are blamed for pathogenesis. These are host components such as genetic predisposition to the diseases and cytokine gene polymorphism which are said to affect the clinical results (4), peripheral components such as smoking and food (5-7), and virulence genotypes of Helicobacter pylori strain (8). Evidences collected show that $H$. pylori infectious power has a high genetic

${ }^{1}$ Recep Tayyip Erdogan University, School of Medicine, Department of Internal Medicine, Division of Gastroenterology, Rize, Turkey, ${ }^{2}$ Karadeniz Technical University, School of Medicine, Gastroenterology, Rize, Turkey, ${ }^{3}$ Karadeniz Technical University, School of Medicine, Microbiology and Clinical Microbiology, Rize, Turkey, and ${ }^{4}$ Karadeniz Technical University, School of Medicine, Pathology, Rize, Turkey

Address for correspondence: R.A. Akdogan, Dr, Recep Tayyip Erdogan University, Department of Internal Medicine, Division of Gastroenterology, Rize, Turkey.

Phone: +905335217248 , Fax: +904642170364

Funding sources: Karadeniz Technical University research fund and identification number is 2007.114.003.3. heterogeneity, which results in the emergence of clinical sequelae (9). It is though that principally four of the bacterial virulence genotypes that have been identified are relevant with the clinical results. These are pore-forming toxin (vacA), cytokine-associated antigen (cagA), blood group antigen binding adhesin (babA) that allows H. Pylori to bind to Lewis b (a-1,3/4-difucosylated) blood group antigens in epithelial cells in the human stomach and iceA (induced by contact with epithelium). Virulence genotype called IceA is induced by the formation of a contact between $H$. $p y$ lori and human epithelial cells and was shown to be associated with peptic ulcer disease (10). Strains producing VacA genotype were shown to be associated with increased gastric damage and peptic ulcer (11). CagA positivity was identified in higher rates in patients with peptic ulcer disease and gastric adenocarcinoma (12-14).

The relation of $H$. pylori infection with gastroesophageal reflux disease (GERD) is a very disputed subject due to suggested conflicting epidemiological data (15-16). One of the suggested hypotheses proposes that the suppression of acid release by corpus gastritis which is caused by $H$. pylori infection and the neutralization of the gastric acid by the ammonia which is produced by the bacterium are protective against the development of gastroesophageal reflux. The studies, which support this view, reported a meaningful relationship between the absence of $H$. $p y$ lori infection and GERD symptoms (17-18). There are also publications stating that the development, relapse and symptoms of 
the gastroesophageal reflux deteriorate with the eradication of $H$. pylori infection (19-20). In contrast with these studies, there are evidences that suggest no clinically significant effect on GERD symptoms with the eradication of $H$. pylori infection (21-24). It is stated that virulent $H$. pylori strains are not protective against GERD development (25-26). In recent prospective researches, it was shown that gastroesophageal reflux symptoms were ameliorated or pre-existing reflux esophagitis improved after $H$. pylori eradication in patients with duodenum ulcer (27-28). The geographical differences between distribution of virulent $H$. pylori strains as well as varying immune response to $H$. pylori have led to the occurrence of conflicting results in literature (29). This immune response, which develops subject to Helicobacter pylori, is determined by the virulence of the primary infectious strain, the genetic disposition of the host to the disease and peripheral factors. Certain cytokines such as interleukin-1 (IL-1), interleukin-2 (IL-2), interleukin-8 (IL-8), interleukin-10 (IL-10) and tumour necrosis factor (TNF) and interferon (IFN) which are released by the body during the immune response which develops in relation to Helicobacter pylori infection affect different mechanisms and lead to tissue destruction. As a result of the emerging inflammation, epithelial cell damage leads to various clinical pictures such as atrophia, dysplasia, ulceration and cancer (30).

The primary genetic factors that affect inflammatory response to $H$. pylori are cytokine gene polymorphisms. Polymorphism is a restricted change that may emerge in the DNA chain. Cytokine gene polymorphisms affect the protein structure of and release by the cytokines. Cytokines and cytokine receptor genes have high polymorphism capability. The studies conducted report that cytokine gene polymorphism impact the high mucosal cytokine release, the inflammatory response and bacterial colonization that develops in the stomach in case of $H$. pylori infection (31).

There is a limited number of studies on the effect of cytokine gene polymorphism on $H$. pylori related diseases. Cytokine gene polymorphism studies dealing with Helicobacter pylori infection frequently concentrate on peptic ulcer and gastric cancer, and increased hypochlorhydria and gastric cancer risk characterized by increase in proinflammatory cytokines caused by IL- $1 \alpha$ gene polymorphism was shown. Gene polymorphisms, which result in a reduced IL-10 expression, are associated with an increased peptic ulcer and gastric cancer risk. This risk is higher for much virulent $H$. pylori strains (31). In this study, we aimed to express the importance of the clinical results that we have obtained as a result of the analysis of Helicobacter pylori virulence genotypes (CagA, VacA, IceA, BabA) and cytokine gene polymorphisms which play an important role in the development of the disease in patients with reflux esophagitis and peptic ulcer.

\section{Method}

\section{Subjects}

50 patients who applied to Karadeniz Technical University (KTU) Faculty of Medicine, Gastroenterology Division out-patient clinic with gastrointestinal complaints and diagnosed with reflux esophagitis and peptic ulcer as a result of physical examination and
Tab. 1. Invitrogen cytokine gene polymorphism analysis table.

\begin{tabular}{|c|c|c|c|c|c|}
\hline Plate1 & Plate 2 & $\begin{array}{c}\text { Cytokine } \\
\text { Gene }\end{array}$ & Allelic characteristic & $\begin{array}{l}\text { Base } \\
\text { length }\end{array}$ & $\begin{array}{l}\text { Internal } \\
\text { Control }\end{array}$ \\
\hline 1 & 49 & IL-1 $\alpha$ & $\mathrm{T}$ at pos- 889 & 220 & 440 \\
\hline 2 & 50 & IL- $1 \alpha$ & C at pos-889 & 220 & 440 \\
\hline 3 & 51 & IL-1 $\beta$ & $\mathrm{C}$ at pos-511 & 215 & 440 \\
\hline 4 & 52 & IL-1 $\beta$ & $\mathrm{T}$ at pos-511 & 215 & 440 \\
\hline 5 & 53 & IL-1 $\beta$ & $\mathrm{T}$ at pos +3952 & 336 & 440 \\
\hline 6 & 54 & IL-1 $\beta$ & C at pos +3952 & 336 & 440 \\
\hline 7 & 55 & IL-1R & C at pos pst1 1970 & 288 & 440 \\
\hline 8 & 56 & IL-1R & T at pos pst1 1970 & 288 & 440 \\
\hline 9 & 57 & IL-1RA & $\mathrm{T}$ at pos mspal 11100 & 297 & 440 \\
\hline 10 & 58 & IL-1RA & C at pos mspal 11100 & 297 & 440 \\
\hline 11 & 59 & IL-4R $\alpha$ & G at pos +1902 & 143 & 440 \\
\hline 12 & 60 & IL-4R $\alpha$ & A at pos +1902 & 143 & 440 \\
\hline 13 & 61 & IL-12 & $\mathrm{C}$ at pos-1188 & 802 & 440 \\
\hline 14 & 62 & IL-12 & A at pos-1188 & 802 & 440 \\
\hline 15 & 63 & IFN- $\gamma$ & A at pos-874 & 277 & 440 \\
\hline 16 & 64 & IFN- $\gamma$ & $\mathrm{T}$ at pos- 874 & 277 & 440 \\
\hline 17 & 65 & TGF- $\beta$ & $\mathrm{C}$ at Codon $10 ; \mathrm{G}$ at Codon 25 & 80 & 440 \\
\hline 18 & 66 & TGF- $\beta$ & $\mathrm{C}$ at Codon $10 ; \mathrm{C}$ at Codon 25 & 80 & 440 \\
\hline 19 & 67 & TGF- $\beta$ & $\mathrm{T}$ at Codon $10 ; \mathrm{G}$ at Codon 25 & 80 & 440 \\
\hline 20 & 68 & TGF- $\beta$ & $\mathrm{T}$ at Codon $10 ; \mathrm{C}$ at Codon 25 & 80 & 440 \\
\hline 21 & 69 & TGF- $\beta$ & $\mathrm{C}$ at Codon 10 & 195 & 440 \\
\hline 22 & 70 & TGF- $\beta$ & $\mathrm{T}$ at Codon 10 & 195 & 440 \\
\hline 23 & 71 & TNF- $\alpha$ & G at pos-308;G at pos-238 & 110 & 440 \\
\hline 24 & 72 & TNF- $\alpha$ & A at pos-308;G at pos-238 & 110 & 440 \\
\hline 25 & 73 & TNF- $\alpha$ & G at pos-308;A at pos- 238 & 110 & 440 \\
\hline 26 & 74 & TNF- $\alpha$ & A at pos-308;A at pos-238 & 110 & 440 \\
\hline 27 & 75 & IL2 & $\mathrm{T}$ at pos-330;G at pos +166 & 562 & 89 \\
\hline 28 & 76 & IL2 & G at pos-330;G at pos +166 & 564 & 89 \\
\hline 29 & 77 & IL2 & G at pos-330;T at pos +166 & 569 & 89 \\
\hline 30 & 78 & IL2 & $\mathrm{T}$ at pos-330;T at pos +166 & 569 & 89 \\
\hline 31 & 79 & IL4 & $\mathrm{T}$ at pos-1098; $\mathrm{T}$ at pos-590 & 557 & 89 \\
\hline 32 & 80 & IL4 & T at pos- $1098 ; \mathrm{C}$ at pos-590 & 557 & 89 \\
\hline 33 & 81 & IL4 & G at pos-1098; $\mathrm{T}$ at pos-590 & 557 & 89 \\
\hline 34 & 82 & IL4 & $\mathrm{G}$ at pos-1098;C at pos-590 & 557 & 89 \\
\hline 35 & 83 & IL4 & $\mathrm{T}$ at pos-590; T at pos-33 & 610 & 89 \\
\hline 36 & 84 & IL4 & T at pos-590;C at pos-33 & 610 & 89 \\
\hline 37 & 85 & IL4 & C at pos-590; T at pos-33 & 610 & 89 \\
\hline 38 & 86 & IL4 & C at pos-590;C at pos-33 & 610 & 89 \\
\hline 39 & 87 & IL6 & G at pos-174;G at pos nt565 & 427 & 89 \\
\hline 40 & 88 & IL6 & C at pos- $174 ; \mathrm{G}$ at pos nt565 & 426 & 89 \\
\hline 41 & 89 & IL6 & G at pos-174;A at pos nt565 & 428 & 89 \\
\hline 42 & 90 & IL6 & C at pos-174;A at pos nt565 & 428 & 89 \\
\hline 43 & 91 & IL10 & G at pos-1082;C at pos-819 & 305 & 89 \\
\hline 44 & 92 & IL10 & G at pos-1082;C at pos-592 & 530 & 89 \\
\hline 45 & 93 & IL10 & A at pos- $1082 ; C$ at pos-819 & 305 & 89 \\
\hline 46 & 94 & IL10 & A at pos-1082;T at pos-819 & 305 & 89 \\
\hline 47 & 95 & IL10 & A at pos- $1082 ; C$ at pos-592 & 530 & 89 \\
\hline 48 & 96 & IL10 & A at pos-1082;A at pos-592 & 530 & 89 \\
\hline
\end{tabular}

assessment and upper gastrointestinal endoscopy were enrolled in this study. The blood, biopsy and faeces samples collected from these patients were analyzed in the microbiology laboratory of KTU, Faculty of Medicine. The age, gender, body mass index, drug use and smoking habit of each patient were determined. Patients with esophageal and gastric surgery history, esophageal and gastric cancer, who refused endoscopy, and who received $H$. pylori eradication treatment in the past were excluded. No patients had 
Tab. 2. Primers used in detecting bacterial virulence factors.

\begin{tabular}{|c|c|c|c|}
\hline Gene & Primer & Primer Sequence & PCR product (bp) \\
\hline \multirow[t]{2}{*}{ CagA } & CagA1F $(+)$ & GATAACAGGCAAGCTTTTGAGG & \multirow{2}{*}{349} \\
\hline & CagA2R(-) & CTGCAAAAGATTGATTGTTTGCGAGA & \\
\hline \multirow[t]{2}{*}{$\operatorname{VacA~s} 1 / \mathrm{s} 2$} & $\mathrm{VA} 1 \mathrm{~F}(+)$ & ATGGAAATACAACAAACACAC & \multirow{2}{*}{$176 / 203$} \\
\hline & VA1XR(-) & CCTGARACCGTTCCTACAGC & \\
\hline \multirow[t]{2}{*}{ VacA s1a } & SS1F (+) & GTCAGCATCACACCGCAAC & \multirow{2}{*}{190} \\
\hline & VA1R (-) & CTGCTTGAATGCGCCAAAC & \\
\hline VacA s1b & SS3F (+) & AGCGCCATACCGCAAGAG & 187 \\
\hline VacA s $1 \mathrm{c}$ & S1C-F & CTYGTTTAGTRGGGYTA & 214 \\
\hline \multirow[t]{2}{*}{$\mathrm{BabA}$} & LBF & AATCCAATTTAATCCAAA & \multirow{2}{*}{190} \\
\hline & LBR & ATAGTTGTCTGAAAGATC & \\
\hline \multirow[t]{2}{*}{$1 \mathrm{ceA} 1$} & IceA1F & GTTGGGTAAGCGTTACAGAATTT & \multirow{2}{*}{567} \\
\hline & IceA1R & CATTGTATATCCTATCATTAC & \\
\hline \multirow[t]{2}{*}{ IceA2 } & IceA2F & GTTGGGTATATCACAATTTAT & \multirow{2}{*}{334} \\
\hline & IceA2R & TTRCCCTATTTTCTAGTAGGT & \\
\hline
\end{tabular}

taken antibiotics or any kind of proton pump inhibitors within the eight weeks before admission. This study was performed according to the Declaration of Helsinki. The informed consent was obtained from all patients and research protocols were approved by the Ethics Committee of Karadeniz Technical University Hospital.

Two biopsy samples were collected from each corpus and antrum from the patients who were diagnosed with reflux esophagitis and peptic ulcer as a result of routine physical examination and assessment, and urease, culture and direct microscopy. The rating of reflux esophagitis was made using Los Angeles classification (32). For histopathological examination, samples were stained with hematoxylen eosine in the pathology department, and presence of helicobacter pylori was examined. While one of the samples was used to detect urease, other samples were cultivated in Brucella agar for culture. Two laminas were prepared for examination in direct microscopy. Also HpSA antigen was searched for in faeces samples of the same patients. Patients with positive results in any two of the urease, culture, direct microscopy or faeces tests were included in the assessment. Blood (6cc) was collected from these patients in EDTA tubes and mononuclear cells were separated. The cells so separated were stored in $-20{ }^{\circ} \mathrm{C}$ until DNA isolation. DNA isolation was performed from mononuclear cells. For DNA isolation MagNA Pure LC (Roche) device and MagNA Pure Total Nucleic Acid Isolation Kit (Roche) were used and DNAs obtained. First, the presence of Beta actin gene was investigated in isolated DNAs using PCR, it was determined whether there was sufficient DNA in the sample, and cytokine gene polymorphism was examined in samples with sufficient DNA.

\section{Genotyping of cytokine gene polymorphisms}

For the genotyping of cytokine gene polymorphism, PCR-SSP (Single Strand Polymorphism) cytokine gene panel of Invitrogen was used (Tab. 1).

For PCR-SSP amplification of each patient a master mix with a total volume of $522.3 \mu 1$ and a DNA mix (Buffer $140 \mu 1$, genomic DNA $50 \mu$, deionized water $329 \mu$, Taq Pol. $(5 \mathrm{U} / \mu \mathrm{l}) 3.3 \mu \mathrm{l}$ ) were prepared. The master mixes prepared were slightly vortexed, and divided into 48 wells on plates in portions of $10 \mu \mathrm{l}$ and then amplified. The PCR product that was obtained with a 2-minute preliminary denaturation at $94^{\circ} \mathrm{C}$, followed by 10 cycles of denaturation for 15 -seconds at $94{ }^{\circ} \mathrm{C}$ in the second round, 1 minute of binding at $65{ }^{\circ} \mathrm{C}, 20$ cycles of denaturation for 15 seconds at $94{ }^{\circ} \mathrm{C}, 50$ seconds of binding at $61^{\circ} \mathrm{C}$, and 30 seconds of extension at $72{ }^{\circ} \mathrm{C}$ was stored at $4{ }^{\circ} \mathrm{C}$ until use. $0.5 \mathrm{X}$ TBE-buffer containing $2 \%$ agarose gel was prepared to electrophorese the amplified PCR products. Samples were loaded in 2 separate gels in 24 wells for each patient and were subject to electrophoresis. Results were evaluated in UV transilluminator. It was checked whether the positive controls in each well functioned or not, and wells showing double bands were accepted as positive and photographed.

Polymerase Chain Reaction for cag A, vacA, ice $A$ and babA genes

Samples that multiply in culture were taken to determine bacterial virulence factors and kept in $10 \%$ glycerol-containing brucella liquid medium at $-20{ }^{\circ} \mathrm{C}$ until use. The biopsies of the samples that did not show any multiplication were kept in $0.9 \% \mathrm{NaCl}$ at $-20{ }^{\circ} \mathrm{C}$. To obtain H. pylori DNA from these samples, the boiling method was used, and PCR was produced from the DNA obtained using the PCR materials from Promega (Tab. 2).

For the detection of VacA and CagA, $10 \mathrm{mmol} / \mathrm{L}$ Tris- $\mathrm{HCl}$ (Ph8), $50 \mathrm{mmol} / \mathrm{L} \mathrm{KCl}, 1.5 \mathrm{mmol} / \mathrm{L} \mathrm{MgCl}_{2}$, deoxynucleotides with a concentration of $200 \mu \mathrm{mol} / \mathrm{L}, 25 \mathrm{pmol}$ forward and reverse primers, and 1.5 U Tag DNA polymerase were used for each PCR reaction. Master mixes prepared in specified quantities were slightly vortexed, and divided into small eppendorfs in portions of $40 \mu 1.10 \mu \mathrm{l}$ DNA sample was added and amplified.

The PCR program consisted of 3 min of pre-incubation at $95^{\circ} \mathrm{C}$, followed by 38 cycles of $1 \mathrm{~min}$ at $95^{\circ} \mathrm{C}, 1 \mathrm{~min}$ at $55^{\circ} \mathrm{C}$ for cagA detection or at $50^{\circ} \mathrm{C}$ for vacAs and $\mathrm{m}$ genotyping, and 1 min at $72{ }^{\circ} \mathrm{C}$. Final extension was performed for $5 \mathrm{~min}$ at $72{ }^{\circ} \mathrm{C}$. The PCR products were inspected by electrophoresis on $2 \%$ agarose gels. Water for cell culture grade (Sigma Chemical, UK) was used as negative controls.

For the detection of babA, polymerase chain reactions (PCRs) were performed in a volume of $50 \mathrm{~L}$ containing $10 \mathrm{mM}$ Tris- $\mathrm{HCl}$ (pH 8.3), $50 \mathrm{mM} \mathrm{KCl}, 1.5 \mathrm{mM} \mathrm{MgCl}, 200 \mathrm{M}$ of each dNTP, $2 \mathrm{~L}$ of genomic DNA released by GR, $2.5 \mathrm{U}$ of Taq DNA polymerase, 
Tab. 3. Comparison of cytokine gene polymorphisms results of patients with refluxe esophagitis and peptic ulcer.

\begin{tabular}{|c|c|c|c|c|c|c|c|c|}
\hline & \multirow{2}{*}{ Cytokine gene } & \multirow{2}{*}{ Allelic characteristic } & \multirow{2}{*}{ bp } & \multicolumn{2}{|c|}{ Reflux esophagitis } & \multicolumn{2}{|c|}{ Peptic ulcus } & \multirow{2}{*}{ P value } \\
\hline & & & & $\mathrm{n}$ & $\%$ & $\mathrm{n}$ & $\%$ & \\
\hline 1 & IL-1 $\alpha$ & T at pos- 889 & 220 & 21 & 84 & 21 & 84 & 1 \\
\hline 2 & IL-1 $\alpha$ & C at pos- 889 & 220 & 24 & 96 & 24 & 96 & 1 \\
\hline 3 & IL-1 $\beta$ & $\mathrm{C}$ at pos-511 & 215 & 23 & 92 & 22 & 88 & 0.637 \\
\hline 4 & IL-1 $\beta$ & $\mathrm{T}$ at pos-511 & 215 & 20 & 80 & 16 & 64 & 0.208 \\
\hline 5 & IL-1 $\beta$ & $\mathrm{T}$ at pos +3952 & 336 & 20 & 80 & 19 & 76 & 0.733 \\
\hline 6 & IL-1 $\beta$ & $\mathrm{C}$ at pos +3952 & 336 & 20 & 80 & 24 & 96 & 0.189 \\
\hline 7 & IL-1R & $\mathrm{C}$ at pos pst1 1970 & 288 & 23 & 92 & 25 & 100 & 0.49 \\
\hline 8 & IL-1R & T at pos pst1 1970 & 288 & 16 & 64 & 16 & 64 & 1 \\
\hline 9 & IL-1RA & T at pos mspa1 11100 & 297 & 24 & 96 & 24 & 96 & 1000 \\
\hline 10 & IL-1RA & $\mathrm{C}$ at pos mspa1 11100 & 297 & 17 & 64 & 21 & 84 & 0.185 \\
\hline 11 & IL-4Ra & G at pos +1902 & 143 & 6 & 24 & 9 & 36 & 0.355 \\
\hline 12 & IL-4Ra & A at pos +1902 & 143 & 25 & 100 & 25 & 100 & 1 \\
\hline 13 & IL-12 & $\mathrm{C}$ at pos- 1188 & 802 & 4 & 16 & 5 & 20 & 1 \\
\hline 14 & IL-12 & A at pos- 1188 & 802 & 10 & 40 & 11 & 44 & 0.774 \\
\hline 15 & IFN- $\gamma$ & A at pos-874 & 277 & 20 & 80 & 18 & 72 & 0.508 \\
\hline 16 & IFN- $\gamma$ & T at pos- 874 & 277 & 16 & 64 & 18 & 72 & 0.544 \\
\hline 17 & TGF- $\beta$ & $\mathrm{C}$ at Codon $10 ; \mathrm{G}$ at Codon 25 & 80 & 18 & 72 & 17 & 68 & 0.758 \\
\hline 18 & TGF- $\beta$ & $\mathrm{C}$ at Codon $10 ; \mathrm{C}$ at Codon 25 & 80 & 3 & 12 & 3 & 12 & 1 \\
\hline 19 & TGF- $\beta$ & $\mathrm{T}$ at Codon $10 ; \mathrm{G}$ at Codon 25 & 80 & 16 & 64 & 20 & 80 & 0.345 \\
\hline 20 & TGF- $\beta$ & $\mathrm{T}$ at Codon $10 ; \mathrm{C}$ at Codon 25 & 80 & 0 & 0 & 0 & 0 & 0 \\
\hline 21 & TGF- $\beta$ & $\mathrm{C}$ at Codon 10 & 195 & 18 & 72 & 14 & 56 & 0.239 \\
\hline 22 & TGF- $\beta$ & $\mathrm{T}$ at Codon 10 & 195 & 15 & 60 & 18 & 72 & 0.37 \\
\hline 23 & TNF- $\alpha$ & G at pos-308;G at pos-238 & 110 & 24 & 96 & 24 & 96 & 1 \\
\hline 24 & TNF- $\alpha$ & A at pos-308;G at pos- 238 & 110 & 16 & 64 & 20 & 80 & 0.345 \\
\hline 25 & TNF- $\alpha$ & $\mathrm{G}$ at pos-308;A at pos- 238 & 110 & 11 & 44 & 15 & 60 & 0.258 \\
\hline 26 & TNF- $\alpha$ & A at pos-308;A at pos-238 & 110 & 6 & 24 & 4 & 16 & 0.725 \\
\hline 27 & IL2 & T at pos-330;G at pos +166 & 562 & 14 & 56 & 19 & 76 & 0.136 \\
\hline 28 & IL2 & G at pos-330;G at pos +166 & 564 & 17 & 68 & 13 & 52 & 0.248 \\
\hline 29 & IL2 & $\mathrm{G}$ at pos-330;T at pos +166 & 569 & 0 & 0 & 1 & 4 & 1 \\
\hline 30 & IL2 & $\mathrm{T}$ at pos- $330 ; \mathrm{T}$ at $\mathrm{pos}+166$ & 569 & 2 & 8 & 9 & 36 & 0.037 \\
\hline 31 & IL4 & $\mathrm{T}$ at pos-1098; $\mathrm{T}$ at pos-590 & 557 & 9 & 36 & 11 & 44 & 0.564 \\
\hline 32 & IL4 & $\mathrm{T}$ at pos- $1098 ; \mathrm{C}$ at pos-590 & 557 & 13 & 52 & 15 & 60 & 0.776 \\
\hline 33 & IL4 & G at pos- $1098 ; T$ at pos- 590 & 557 & 2 & 8 & 1 & 4 & 1 \\
\hline 34 & IL4 & G at pos- $1098 ; \mathrm{C}$ at pos- 590 & 557 & 6 & 24 & 4 & 16 & 0.725 \\
\hline 35 & IL4 & T at pos-590; $\mathrm{T}$ at pos-33 & 610 & 10 & 40 & 8 & 32 & 0.769 \\
\hline 36 & IL4 & $\mathrm{T}$ at pos-590; $\mathrm{C}$ at pos-33 & 610 & 8 & 32 & 6 & 24 & 0.754 \\
\hline 37 & IL4 & $\mathrm{C}$ at pos- $590 ; \mathrm{T}$ at pos-33 & 610 & 8 & 32 & 4 & 16 & 0.321 \\
\hline 38 & IL4 & $\mathrm{C}$ at pos- $590 ; \mathrm{C}$ at pos-33 & 610 & 11 & 44 & 10 & 40 & 1 \\
\hline 39 & IL6 & G at pos-174;G at pos nt565 & 427 & 16 & 64 & 18 & 72 & 0.762 \\
\hline 40 & IL6 & $\mathrm{C}$ at pos- $174 ; \mathrm{G}$ at pos nt565 & 426 & 6 & 24 & 7 & 28 & 1 \\
\hline 41 & IL6 & G at pos-174;A at pos nt565 & 428 & 1 & 4 & 1 & 4 & 1 \\
\hline 42 & IL6 & C at pos-174; A at pos nt565 & 428 & 7 & 28 & 10 & 40 & 0.551 \\
\hline 43 & IL10 & G at pos- $1082 ; \mathrm{C}$ at pos- 819 & 305 & 20 & 80 & 21 & 84 & 1 \\
\hline 44 & IL10 & G at pos- $1082 ; \mathrm{C}$ at pos-592 & 530 & 16 & 64 & 18 & 72 & 0.762 \\
\hline 45 & IL10 & A at pos- $1082 ; \mathrm{C}$ at pos- 819 & 305 & 18 & 72 & 24 & 96 & 0.049 \\
\hline 46 & IL10 & A at pos- $1082 ; \mathrm{T}$ at pos- 819 & 305 & 20 & 80 & 16 & 64 & 0.345 \\
\hline 47 & IL10 & A at pos- $1082 ; \mathrm{C}$ at pos-592 & 530 & 14 & 56 & 21 & 84 & 0.062 \\
\hline 48 & IL10 & A at pos- $1082 \mathrm{~A}$ at pos-592 & 530 & 14 & 64 & 16 & 64 & 0.773 \\
\hline
\end{tabular}

and $25 \mathrm{pmol}$ of specific forward and reverse primers. Master mixes prepared in specified quantities were slightly vortexed, and divided into small eppendorfs in portions of $40 \mu 1.10 \mu \mathrm{l}$ DNA sample was added and amplified.

The PCR program for babA comprised 30 cycles of 1 min at $94{ }^{\circ} \mathrm{C}, 1 \mathrm{~min}$ at $38^{\circ} \mathrm{C}$, and $1 \mathrm{~min}$ at $72^{\circ} \mathrm{C}$. After amplification 10 $\mathrm{mmol} / \mathrm{L}$ of $\mathrm{PCR}$ product was electrophoresed on $1.7 \%$ agarose gel and examined under UV illumination.
For Ice A1, IceA2, 10 mmol/L Tris-HCl (Ph8.3), 50 mmol/L $\mathrm{KCl}, 1.5 \mathrm{mmol} / \mathrm{L} \mathrm{MgCl}_{2}$, deoxynucleotides with a concentration of $200 \mu \mathrm{mol} / \mathrm{L}, 0.5 \mu \mathrm{M}$ primers, and 2.5 U Tag DNA polymerase were used. The amplification cycles (iceA) consisted of an initial denaturation of target DNA at $94{ }^{\circ} \mathrm{C}$ for 9 min and then denaturation at $94{ }^{\circ} \mathrm{C}$ for $1 \mathrm{~min}$, primer annealing at $60{ }^{\circ} \mathrm{C}$ for $1 \mathrm{~min}$ and extension at $72{ }^{\circ} \mathrm{C}$ for $1 \mathrm{~min}(35$ cycles $)$. The final cycle included an extension step for $5 \mathrm{~min}(6,9,14 \mathrm{PCR})$ products were 
Tab. 4. Comparison of the bacterial virulence factors in reflux esophgitis and peptic ulcer patients.

\begin{tabular}{lccccccc}
\hline & \multicolumn{2}{c}{$\begin{array}{c}\text { Reflux } \\
\text { esphagitis }\end{array}$} & & \multicolumn{2}{c}{ Peptic ulcus } & \\
\cline { 2 - 3 } \cline { 5 - 6 } \cline { 5 - 6 } & $\mathrm{n}$ & $\%$ & & $\mathrm{n}$ & $\%$ & \\
\hline cagA positive & 19 & 76 & & 18 & 72 & 0.747 \\
vacA s1 positive & 19 & 76 & & 20 & 72 & 0.733 \\
vacA s2 positive & 6 & 24 & & 5 & 20 & 0.733 \\
Ice A1 positive & 10 & 40 & & 8 & 32 & 0.556 \\
Ice A2 positive & 7 & 28 & & 6 & 24 & 0.747 \\
Bab A positive & 13 & 52 & & 12 & 48 & 0.777 \\
\hline
\end{tabular}

visualised by agarose $2 \%$ gel electrophoresis. $0.5 \mathrm{X}$ TBE-buffer containing $2 \%$ agarose gel was prepared and used to electrophorese the amplified PCR products. Results were evaluated in UV transilluminator. Wells that showed bands were accepted as positive and photographed.

\section{Data analysis}

The statistical analysis of cytokine gene polymorphism was performed using the SPSS Windows 9.0 program. Statistical significance between the groups were calculated with chi-square test. The mean values were compared using the Student's t-test. Age, gender and accompanying diseases were evaluated with univariate analysis. $\mathrm{p}<0.05$ value was considered as statistically significant.

\section{Results}

This study was carried out between March 2007 and November 2007 at Karadeniz Technical University, Faculty of Medicine, Gastroenterology Department, Pathology Department, Microbiology and Clinical Microbiology Department. A total of 50 patients comprised of 25 patients with esophagitis and 25 patients with peptic ulcer having positive results from at least any two of $H$. pylori diagnosis tests were enrolled in the study.

The ages of the patients varied between 19-70. The mean age of patients with reflux esophagitis was $41.80 \pm 12.98$. The mean age of patients with peptic ulcer was $41.56 \pm 13.65$. When the mean age was examined in both patient groups, no statistical difference was identified $(\mathrm{p}=0.949)$. The number of female subjects in reflux esophagitis group was 13 (52\%) while the number male subjects was $12(48 \%)$. Number of female subjects in reflux esophagitis group was $14(56 \%)$ while the number male subjects was 11 (48 $\%)$. No statistical difference was identified between the two groups in terms of distribution of genders $(p=0.777)$.

When body mass indexes of patients with reflux esophagitis and peptic ulcer were evaluated, BMI was found to be $23.18 \pm 3.16$ in the patient group with reflux esophagitis and 23.20 \pm 3.54 in the patient group with peptic ulcer. No statistically significant difference was identified between the two groups in terms of body mass index $(\mathrm{p}=0.832)$.

When smoking rates were evaluated in patients with reflux esophagitis and peptic ulcer, number of smokers was found to be 7 in the reflux esophagitis group and 8 in the peptic ulcer group. No statistically significant difference was identified between the two groups in terms of smoking rate $(\mathrm{p}=0.758)$.
None of the patients with reflux esophagitis and peptic ulcer used corticosteroids, nonsteroidal anti-inflammatory and anticoagulant agents as a drug.

\section{Findings related to cytokine gene polymorphism in reflux esopha-} gitis and peptic ulcer patients

When cytokine gene polymorphisms of patients with reflux esophagitis and peptic ulcer are compared, statistically significant differences were detected with IL-2 $-330 \mathrm{~T}+166 \mathrm{~T}(\mathrm{p}=0.037)$ and IL10 -1082A; 819C ( $\mathrm{p}=0.049)$. IL-2 $-330 \mathrm{~T}+166 \mathrm{~T}$ polymorphism was determined as positive in 2 reflux esophagitis patients and in 9 peptic ulcer patients. IL10-1082A; -819C was detected as positive in 18 patients with reflux esophagitis and in 24 patients with peptic ulcer. When other polymorphisms are viewed, IL-1 $\alpha-889 \mathrm{~T}$, IL-1 $\alpha$ -889C, IL-1 $\beta-511 \mathrm{C}$, IL-1 $\beta$-511T, IL-1 $\beta+3962 \mathrm{~T}$, IL-1 $\beta+3962 \mathrm{C}$, IL-1R pst1 1970C, IL-1RA mspa1 11100T, IL-4Ra +1902A, IL$4 \mathrm{R} \alpha+1902 \mathrm{G}$, TNF- $\alpha-308 \mathrm{G} ;-238 \mathrm{G}$ and IL10 -1082G; $-819 \mathrm{C}$ were detected in both patient groups concurrently with a positivity rate as high as above $80 \%$. In contrast IL- $12-1188 \mathrm{C}$, TGF- $\beta$ 10 codonC; 25 codonC, TGF- $\beta 10$ codonT; 25 codonC, TNF- $\alpha$ $-308 \mathrm{~A}$; -238A, IL-2 -330G; +166T, IL-4 -1098G; -590T, IL-4 $-1098 \mathrm{G} ;-590 \mathrm{C}$ and IL-6 -174G; nt565A were detected in both groups concurrently with a positivity rate below $20 \%$. In terms of TGF- $\beta 10$ codonC; 25 codonC no positivity was detected in any of the two groups (Tab. 3).

Findings related to bacterial virulence factors in reflux esophagitis and peptic ulcer patients

The findings were obtained by boiling the DNA of the bacteria obtained using the culture method or direct biopsy in patients with reflux esophagitis and peptic ulcer who proved to be positive in any two of Helicobacter pylori diagnosis tests, and bacterial virulence factors were examined using PCR method (Tab. 4).

CagA, a bacterial virulence factor, was detected as positive in 19 of the patients with reflux esophagitis (76\%) and in 18 of the patients with peptic ulcer (72\%). No statistical difference was identified between the two patient groups in terms of CagA as a virulence factor $(\mathrm{p}=1.000)$.

VacA, a $H$. pylori virulence factor, is divided into two as s1ve $\mathrm{s} 2$ as a signal sequence. $\mathrm{S} 1$ is separated into three as $\mathrm{s} 1 \mathrm{a}, \mathrm{s} 1 \mathrm{~b}$ and s1c. s1 and s2 were detected as positive in respectively $19(76 \%)$ and $6(24 \%)$ of the patients with reflux esophagitis, whereas s1 and s 2 were detected as positive in respectively $20(80 \%)$ and 5 $(20 \%)$ of the patients with peptic ulcer. 19 of the patients with reflux esophagitis $(76 \%)$ and 20 of the patients with peptic ulcer $(80 \%)$ in who S1 was detected were found to have s1a. 6 of the patients with reflux esophagitis $(24 \%)$ and 5 of the patients with peptic ulcer $(20 \%)$ in who S1 was detected were found to have sb1. S1c was not detected as positive in any of the patients. No statistical difference was detected between the two groups in terms of s1, s1a, s1b, and s2 ( $\mathrm{p}=0.733)$.

When we examined IceA 1 and IceA2 virulence factors, IceA1 was detected as positive in 10 of the patients with reflux esophagitis $(40 \%)$ and in 8 of the patients with peptic ulcer (32\%). In the case of IceA2 positivity was detected in 7 of the patients with 
reflux esophagitis ( $28 \%$ ) and in 6 of the patients with peptic ulcer (24\%). From the results obtained, no statistically significant difference was determined between the two patient groups (IceA1 $\mathrm{p}=0,556$, IceA2 $\mathrm{p}=0,747$ ).

BabA positivity rate was detected in 13 of the patients with reflux esophagitis ( $52 \%$ ) and in 14 of the patients with peptic ulcer $(56 \%)$, however this result is not statistically significant $(\mathrm{p}=1.000)$.

\section{Discussion}

Helicobacter pylori is a gram-negative microorganism that may lead to various diseases such as chronic gastritis, peptic ulcer, mucosa-associated lymphoid tissue (MALT) lymphoma, and gastric cancer. A majority of the people infected with Helicobacter pylori is asymptomatic, but the above mentioned diseases can be seen in up to $15-20 \%$ of this population. Basic factors that play a role in the development of diseases associated with Helicobacter pylori are specific virulence factors, genetic factors of the host and peripheral factors (33).

In this study, which we conducted on patients with peptic ulcer and gastroesophageal reflux, infected with Helicobacter pylori, we aimed to assess the basic factors that were thought to play a role in the development of the disease. For this reason, use of drugs, smoking and body mass index were evaluated as peripheral factors. VacA, CagA, BabA and Ice A virulence genotypes, which are the specific virulence factors of the bacterium were studied with cytokine gene polymorphisms of IL-1, IL-2, IL-4, IL-6, IL-10, IL-12, interferon- $\gamma$, TNF- $\alpha$, and TGF- $\beta 1$ that are known to affect the immune response in the patients.

CagA positivity was detected as $76 \%$ in the reflux esophagitis group, $72 \%$ in the peptic ulcer group, and $74 \%$ as average when all patients are taken together. In studies conducted in our country, cagA positivity is reported to be in the range of $59 \%$ and $78 \%$. Various studies conducted show that cagA positivity is associated with peptic ulcer formation. In a study conducted by Aydin et al. in our country, it was reported that cagA positivity was associated with an increased duodenal ulcer and gastric cancer risk (34). In another study performed by Leodolter et al, cagA positivity was detected to be higher in patients with duodenal ulcer and GERD than in patients with functional dyspepsia (respectively, $40 \%$, $83 \%, 80 \%$ ), and this result was similar to our data (26).

VacA, a H. pylori virulence factor, is divided into two subtypes as s1ve s2 as a signal sequence. In our study, no statistically significant was detected in terms of vacA s1, vacA s1a, vacA s1b and vacA s1c and vacA s2 between the two groups with reflux esophagitis and peptic ulcer $(\mathrm{p}=0.733)$. S1c was not detected as positive in any of the patients.

When all patients are evaluated together, iceA1 was detected in the rate of $36 \%$, iceA2 was detected in the rate of $26 \%$. Erzin et al on patients with dyspepsia, iceA1 was determined as 74.7 and IceA 2 as $25.3 \%$, iceA 1 rates in our region were found to be lower than in Istanbul. However, iceA1 is much dominant compared to iceA2 in our country, and is consistent with Holland (35), Japan (36) and Hong Kong (37) findings. Studies conducted in USA (38), Columbia (39) and Brazil showed that iceA2 was dominant
(40). Peek et al (41) and van Doorn et al (35) reported meaningful association between iceA1 genotype and peptic ulcer, and no statistically significant difference was found in our study between the two groups with reflux esophagitis and peptic ulcer in terms of iceA1 and iceA2 (IceA1 p=0,556, IceA2 p=0,747).

BabA was detected as positive in 13 of the patients with reflux esophagitis (52\%) and in 14 of the patients with peptic ulcer (56 $\%$ ). The mean babA positivity was reported as $52.5 \%$, similar to babA positivity in our study which was detected as $54 \%$ in a study in Turkey (42). In our study no statistically significant difference was found between the two groups with reflux esophagitis and peptic ulcer in terms of babA, and a babA positivity of average $54 \%$ was detected $(p=1.000)$.

In this study, where we assessed reflux esophagitis and peptic ulcer patients in terms of bacterial virulence genotypes, it was found that the subjects expressed multi Helicobacter pylori virulence genotypes (cagA, vacA, babA). Similar to our findings, in the study performed by Leodolter et al, cagA, vacA, and babA positivity was shown to be higher in patients with duodenal ulcer and gastroesophageal reflux disease than in patients with functional dyspepsia. The literature stresses the importance of multi virulence genotype expression, which increases inflammation and plays role in the development of diseases associated with Helicobacter pylori (43).

In this study, we have performed in the East Black Sea Region, the results we have achieved in terms of expression rates of virulence genotypes show similarity to studies conducted in other regions of our country.

Cytokines are regulators of host immune response in situations such as infection, inflammation and trauma. In such situations, some cytokines increase inflammation and are called proinflammatory cytokines. Primary proinflammatory cytokines are IL-1, IL-2, TNF $\alpha$, IL-6, IL-8, IL-11, IL-12 and chemokines. Some cytokines are responsible for suppressing proinflammatory cytokine activity. These are called anti-inflammatory cytokines. Primary anti-inflammatory cytokines are IL-4, IL-10, IL-13, IL-16, IFN- $\alpha$.

Studies on cytokine polymorphisms associated with Helicobacter pylori frequently focus on gastric cancer, and increased risk of hypochlorhydria and gastric cancer characterized with increase in proinflammatory cytokines as a result of IL- $1 \beta$ gene polymorphism was shown (44). Predisposition to increased gastric atrophia and gastric cancer associated with IL-2 gene polymorphism has been reported in the literature. Won $\mathrm{HH}$ et al reported that interleukin 10 polymorphisms differentially influence the risk of gastric cancer in East Asians and Caucasians. There is a limited number of studies relating to gastroesophageal reflux disease and cytokine gene polymorphism. Muramatsu et al reported increased IL-1 $\beta$ $511 \mathrm{C} / \mathrm{T}$ polymorphism in patients with reflux esophagitis (40).

In this study, that we have conducted on patients with reflux esophagitis and peptic ulcer, IL-2 $-330 \mathrm{~T}+166 \mathrm{~T}$ polymorphism was determined as positive in 9 peptic ulcer patients and only in 2 reflux esophagitis patients. IL-2 T/T polymorphism was much frequently detected in patients with peptic ulcer than in patients with reflux esophagitis, and this difference was found to be statistically significant $(\mathrm{p}=0.037)$. 
T cell response, which develops in subject to Helicobacter pylori, is dominantly seen as Thelper 1 (Th1) response in humans (46). Th1 cells produce IL-2 and such responses are associated with the expression of proinflammatory cytokines such as IFN- $\gamma$ and TNF- $\alpha$. IL-2 is a strong proinflammatory cytokine. Macrophages secrete proinflammatory factors when induced by Th1 cells. IL-2 induces antibody production with the proliferation of active $\mathrm{T}$ and B cells. They induce IL-3, IL-4, IL-5, IL-6, GM-CSF, INF- $\gamma$, TNF- $\beta$ and TGF- $\beta$ syntheses. Cytotoxic T lymphocytes ensure the activation of NK cells and neutrophils. Increased IL-2 inhibits gastric acid secretion with Th1 response, and results in precancerous gastric atrophia, metaplasia and dysplasia. In their study, Togawa et al determined thrice increase in gastric atrophia prevalence in $2 \mathrm{~T} / \mathrm{T}$ genotype compared to IL $2 \mathrm{G} / \mathrm{G}$ genotype 47 . Increased IL-2 $\mathrm{T} / \mathrm{T}$ cytokine gene polymorphism we have determined in patients with peptic ulcer in this study is supported by immunologic evidences, which play a role in peptic ulcer development.

In our study, IL10 -1082A; -819C polymorphism was detected as positive in 18 patients with reflux esophagitis and in 24 patients with peptic ulcer. IL-10 -1082A; -819C polymorphism was slightly much more detected in patients with peptic ulcer than in patients with reflux esophagitis, and this difference was found to be statistically significant $(\mathrm{p}=0.049)$.

IL-10 is a multi-functional anti-inflammatory cytokine. IL-10 is secreted from Th 2 cells, thymocytes, monocytes, macrophages, $\mathrm{B}$ cells and Langerhans cells. Th 1 helps to suppress cell response and inhibit IL-2 and IFN synthesis. IL-10 induces B cell proliferation and differentiation. It inhibits IL-1, IL-6, IL-8, GM-CSF, G-CSF synthesis, suppresses inflammation and has a suppressive effect on type Th1 immune response. Low IL-10 production in patients infected with Helicobacter pylori results in increased gastric inflammation intensity, hypochlorhydria and increased risk of gastric atrophia and gastric cancer. Lu et al (48) reported increased risk of gastric cancer and peptic ulcer associated with IL-10 gene polymorphism. In another study conducted by El-Omar, it is stated that anti-inflammatory cytokines such as IL-10 have two-fold more effect in the formation of extracardiac gastric cancer (44).

In conclusion, this preliminary study establishes the importance of multi bacterial virulence factors and the cytokine gene polymorphisms that shape the immune response in the host on the development of peptic ulcer in patients with reflux esophagitis and peptic ulcer, infected with Helicobacter pylori. It was found that the subjects with reflux esophagitis and peptic ulcer expressed multi Helicobacter pylori virulence genotypes (cagA, vacA, iceA). In Turkey, $H$. pylori infection caused by these multi genotypes are much prevalent compared to western countries (49-50). This result may be related to a wide prevalence of $H$. pylori and childhood infections in Turkey. H. pylori may undergo genetic changes during the long-term colonization starting from the childhood (51). It was concluded that prevalence of multi-strain colonization should be taken into account when planning treatment and also researches relating to the pathogenesis of $H$. pylori infection.

IL-2 T/T polymorphism and IL-10 - 1082A; -819C polymorphism, which was detected in patients with peptic ulcer, are considered to have an effect on peptic ulcer formation.
As a result, consistent with literature, multi Helicobacter pylori virulence genotype expression was found to be important in the development of diseases associated with Helicobacter pylori. However, it was concluded that cytokine gene polymorphisms may also play a role in peptic ulcer development. It is considered that a detection of multi virulence genotype expression and cytokine gene polymorphism may provide guidance in detecting prognosis in patients infected with Helicobacter pylori in studies to be conducted in the future years.

Which clinical pictures of Helicobacter pylori will result is determined primarily by the bacterial virulence factors and the immune system of the host, and it has been concluded that broadscale meta-analyses will be required where HLA tissue groups, inflammation mediators, parietal cell antibodies, acid secretion and infection age, which were shown to influence this result have to be evaluated together.

\section{References}

1. Dunn BE, Cohen H, Blaser MJ. Helicobacter pylori. Clin Microbiol Rev 1997; 10: 720-741.

2. Kuipers EJ. Review article: Exploring the link between helicobacter pylori and gastric cancer. Aliment Pharmacol Ther 1999; 13 Suppl 1: 3-11.

3. Iarc working group on the evaluation of carcinogenic risks to humans. Schistosomes, liver flukes and helicobacter pylori. Lyon, 7-14 june 1994. IARC Monogr Eval Carcinog Risks Hum 1994; 61: 1-241.

4. Go MF. What are the host factors that place an individual at risk for helicobacter pylori-associated disease? Gastroenterology 1997; 113: S15-20.

5. Kurata JH, Nogawa AN. Meta-analysis of risk factors for peptic ulcer. Nonsteroidal antiinflammatory drugs, helicobacter pylori, and smoking. J Clin Gastroenterol 1997; 24: 2-17.

6. Martin DF, Montgomery E, Dobek AS, Patrissi GA, Peura DA. Campylobacter pylori, nsaids, and smoking: Risk factors for peptic ulcer disease. Am J Gastroenterol 1989; 84: 1268-1272.

7. McCarthy DM. Smoking and ulcer--time to quit. N Engl J Med. 1984; 311: 726-728.

8. Brubaker RR. Mechanisms of bacterial virulence. Annu Rev Microbiol 1985; 39: 21-50.

9. Blaser MJ, Berg DE. Helicobacter pylori genetic diversity and risk of human disease. J Clin Invest 2001; 107: 767-773.

10. Gerhard M, Lehn N, Neumayer N, Boren T, Rad R, Schepp W et al. Clinical relevance of the helicobacter pylori gene for blood-group antigenbinding adhesin. Proc Natl Acad Sci USA 1999; 96: 12778-12783.

11. Figueiredo C, Machado JC, Yamaoka Y. Pathogenesis of helicobacter pylori infection. Helicobacter 2005; 10 (Suppl 1): 14-20.

12. Crabtree JE, Taylor JD, Wyatt JI, Heatley RV, Shallcross TM, Tompkins DS et al. Mucosal IgA recognition of helicobacter pylori 120 kda protein, peptic ulceration, and gastric pathology. Lancet 1991; 338: 332-335.

13. Covacci A, Censini S, Bugnoli M, Petracca R, Burroni D, Macchia G et al. Molecular characterization of the 128-kda immunodominant antigen of helicobacter pylori associated with cytotoxicity and duodenal ulcer. Proc Natl Acad Sci USA 1993; 90: 5791-5795.

14. Blaser MJ, Perez-Perez GI, Kleanthous H, Cover TL, Peek RM, Chyou PH et al. Infection with helicobacter pylori strains possessing caga is associated with an increased risk of developing adenocarcinoma of the stomach. Cancer Res 1995; 55: 2111-2115. 
15. Vakil NB. Review article: Gastro-oesophageal reflux disease and helicobacter pylori infection. Aliment Pharmacol Ther 2002; 16 (Suppl 1): 47-51.

16. Clark GW. Effect of helicobacter pylori infection in barrett's esophagus and the genesis of esophageal adenocarcinoma. World J Surg 2003; 27: 994-998.

17. Fallone CA, Barkun AN, Gottke MU, Best LM, Loo VG, Veldhuyzen van Zanten $\mathrm{S}$ et al. Association of helicobacter pylori genotype with gastroesophageal reflux disease and other upper gastrointestinal diseases. Am J Gastroenterol 2000; 95: 659-669.

18. Raghunath A, Hungin AP, Wooff D, Childs S. Prevalence of helicobacter pylori in patients with gastro-oesophageal reflux disease: Systematic review. BMJ 2003; 326: 737.

19. Fallone CA, Barkun AN, Friedman G, Mayrand S, Loo V, Beech R et al. Is helicobacter pylori eradication associated with gastroesophageal reflux disease? Am J Gastroenterol 2000; 95: 914-920.

20. Cremonini F, Di Caro S, Delgado-Aros S, Sepulveda A, Gasbarrini G, Gasbarrini A et al. Meta-analysis: The relationship between helicobacter pylori infection and gastro-oesophageal reflux disease. Aliment Pharmacol Ther 2003; 18: 279-289.

21. Malfertheiner P, O'Connor HJ, Genta RM, Unge P, Axon AT. Symposium: Helicobacter pylori and clinical risks--focus on gastro-oesophageal reflux disease. Aliment Pharmacol Ther 2002; 16 (Suppl 3): 1-10.

22. Vakil N, Hahn B, McSorley D. Recurrent symptoms and gastro-oesophageal reflux disease in patients with duodenal ulcer treated for helicobacter pylori infection. Aliment Pharmacol Ther 2000; 14: 45-51.

23. Laine L, Sugg J. Effect of helicobacter pylori eradication on development of erosive esophagitis and gastroesophageal reflux disease symptoms: A post hoc analysis of eight double blind prospective studies. Am J Gastroenterol 2002; 97: 2992-2997.

24. Laine L, Dhir V. Helicobacter pylori eradication does not worsen quality of life related to reflux symptoms: A prospective trial. Aliment Pharmacol Ther 2002; 16: 1143-1148.

25. Kiltz U, Pfaffenbach B, Schmidt WE, Adamek RJ. The lack of influence of caga positive helicobacter pylori strains on gastro-oesophageal reflux disease. Eur J Gastroenterol Hepatol 2002; 14: 979-984.

26. Leodolter A, Wolle K, Peitz U, Ebert M, Günther T, Kahl S et al. Helicobacter pylori genotypes and expression of gastritis in erosive gastrooesophageal reflux disease. Scand J Gastroenterol 2003; 38: 498-502.

27. Malfertheiner P, Dent J, Zeijlon L, Sipponen P, Veldhuyzen van Zanten, Burman CF et al. Impact of helicobacter pylori eradication on heartburn in patients with gastric or duodenal ulcer disease - results from a randomized trial programme. Aliment Pharmacol Ther 2002; 16: 1431-1442.

28. Ishiki K, Mizuno M, Take $S$ et al. Helicobacter pylori eradication improves pre-existing reflux esophagitis in patients with duodenal ulcer disease. Clin Gastroenterol Hepatol 2004; 2: 474-479.

29. Covacci A, Telford JL, Del Giudice G, Parsonnet J, Rappuoli R. Helicobacter pylori virulence and genetic geography. Science 1999; 284 : 1328-1333.

30. Robinson K, Argent RH, Atherton JC. The inflammatory and immune response to helicobacter pylori infection. Best Pract Res Clin Gastroenterol. 2007; 21: 237-259.

31. Rad R, Dossumbekova A, Neu B et al. Cytokine gene polymorphisms influence mucosal cytokine expression, gastric inflammation, and host specific colonisation during helicobacter pylori infection. Gut 2004; 53: 10821089 .

32. Lundell LR, Dent J, Bennett JR et al. Endoscopic assessment of oesophagitis: Clinical and functional correlates and further validation of the los angeles classification. Gut 1999; 45: 172-180.
33. Mobley HL. Helicobacter pylori factors associated with disease development. Gastroenterology 1997; 113: S21-28.

34. Aydin F, Kaklikkaya N, Ozgur $O$ et al. Distribution of vaca alleles and caga status of helicobacter pylori in peptic ulcer disease and non-ulcer dyspepsia. Clin Microbiol Infect 2004; 10: 1102-1104.

35. van Doorn LJ, Figueiredo $\mathbf{C}$, Sanna $\mathbf{R}$ et al. Clinical relevance of the caga, vaca, and icea status of helicobacter pylori. Gastroenterology 1998; 115: 58-66.

36. Ito $\mathbf{Y}$, Azuma T, Ito $\mathrm{S}$ et al. Sequence analysis and clinical significance of the icea gene from helicobacter pylori strains in japan. J Clin Microbiol 2000; 38: 483-488.

37. Wong BC, Yin Y, Berg DE et al. Distribution of distinct vaca, caga and icea alleles in helicobacter pylori in Hong Kong. Helicobacter 2001; 6: 317-324.

38. Yamaoka Y, Kodama T, Gutierrez $\mathrm{O}$ et al. Relationship between helicobacter pylori icea, caga, and vaca status and clinical outcome: Studies in four different countries. J Clin Microbiol 1999; 37: 2274-2279.

39. Ashour AA, Collares GB, Mendes EN et al. Icea genotypes of helicobacter pylori strains isolated from brazilian children and adults. J Clin Microbiol 2001; 39: 1746-1750.

40. Muramatsu A, Azuma T, Okuda T et al. Association between interleukin-1beta-511c/t polymorphism and reflux esophagitis in japan. J Gastroenterol 2005; 40: 873-877.

41. Peek RM, Jr., Thompson SA, Donahue JPet al. Adherence to gastric epithelial cells induces expression of a helicobacter pylori gene, icea, that is associated with clinical outcome. Proc Assoc Am Physicians 1998; 110: 531-544.

42. Erzin Y, Koksal V, Altun S et al. Prevalence of helicobacter pylori vaca, caga, cage, icea, baba2 genotypes and correlation with clinical outcome in turkish patients with dyspepsia. Helicobacter 2006; 11: 574-580.

43. Zambon CF, Navaglia F, Basso D, Rugge M, Plebani M. Helicobacter pylori baba2, caga, and s1 vaca genes work synergistically in causing intestinal metaplasia. J Clin Pathol 2003; 56: 287-291.

44. El-Omar EM, Rabkin CS, Gammon MD et al. Increased risk of noncardia gastric cancer associated with proinflammatory cytokine gene polymorphisms. Gastroenterology 2003; 124: 1193-1201.

45. Won HH, Kim JW, Kim MJ, Kim S, Park JH, Lee KA. Interleukin 10 polymorphisms differentially influence the risk of gastric cancer in East Asians and Caucasians. Cytokine 2010; 51 (1): 73-7. Epub 2010 Apr 2.

46. Vorobjova T, Watanabe T, Chiba T. Helicobacter pylori immunology and vaccines. Helicobacter 2008; 13 (Suppl 1): 18-22.

47. Togawa S, Joh T, Itoh M et al. Interleukin-2 gene polymorphisms associated with increased risk of gastric atrophy from helicobacter pylori infection. Helicobacter 2005; 10: 172-178.

48. Lu W, Pan K, Zhang L et al. Genetic polymorphisms of interleukin (IL)-1b, IL-1rn, IL-8, IL-10 and tumor necrosis factor \{alpha\} and risk of gastric cancer in a chinese population. Carcinogenesis 2005; 26: 631-636.

49. Saribasak H, Salih BA, Yamaoka Y, Sander E. Analysis of helicobacter pylori genotypes and correlation with clinical outcome in Turkey. J Clin Microbiol 2004; 42: 1648-1651.

50. Sezikli M, Guliter S, Apan TZ et al. Frequencies of serum antibodies to helicobacter pylori caga and vaca in a turkish population with various gastroduodenal diseases. Int J Clin Pract 2006; 60: 1239-1243.

51. Kersulyte D, Chalkauskas H, Berg DE. Emergence of recombinant strains of helicobacter pylori during human infection. Mol Microbiol 1999; 31: 31-43.

Received March 15, 2012. Accepted October 27, 2013. 